\title{
Evaluation of 2007 and 2018 Turkish Earthquake Code For the Provinces of Erzurum and Erzincan
}

\author{
Erdem Bayrak (Corresponding author) \\ Department of Geology, Oltu Earth Sciences Faculty, \\ Ataturk University, 25400 Oltu-Erzurum, Turkey \\ E-mail: erdmbyrk@gmail.com
}

\begin{abstract}
Turkey is located on seismically very active region. Therefore, very destructive earthquakes occurred in Turkey and around, and caused loss of life and property. After the 1939 Erzincan earthquake, one of the biggest earthquakes in the instrumental period, earthquake codes were started to be prepared and these codes were updated in certain periods. Finally, "Turkey Building Seismic Code" entered into force on 01.01.2019, the earthquake hazard maps updated and new approaches in parameters calculation have been introduced. The forces affecting structures during the earthquake can be determined by static and dynamic methods. However, in order to make the calculations more practical, the spectral analysis method, which is the static method, is widely used. This method is named as design spectrum in earthquake codes. In this study, the spectral acceleration values were obtained as defined in Turkish Seismic Code 2007 (TSC 2007) and Turkish Building Seismic Code 2018 (TBSC 2018) using different soil types for Erzurum and Erzincan provinces. The location where the design spectra will be calculated is located in the first (Erzincan) and second (Erzincan) earthquake zone according to the 1996 earthquake zones map. The acceleration spectra were calculated for an earthquake with a probability of exceeding $10 \%$ probability in 50 years for the planned structure (return period 475 years, Earthquake Ground Motion Level-2). The design spectra were prepared in graphical and tabular form and the difference between them was observed. One of the biggest differences of TBSC 2018 from the old code is the abolition of the concept of earthquake zone and the introduction of the concept of direct ground acceleration. Another difference is the change of soil groups. Since these parameters are closer to reality, the calculations made with TBSC 2018 are more reliable.
\end{abstract}

Keywords: Earthquake Hazard Map, Spectral Acceleration, TBSC 2018, TSC 2007

DOI: $10.7176 /$ JSTR/5-12-07

\section{Özet}

Türkiye sismik olarak çok aktif bir bölgede bulunmaktadır. Bu nedenle Türkiye ve civarında çok yıkıcı depremler meydana gelmekte, bu depremler nedeni ile çok sayıda can ve mal kaybı yaşanmaktadır. Aletsel dönemde meydana gelen en büyük depremlerden biri olan 1939 Erzincan depremi sonrası deprem yönetmelikleri hazırlanmaya başlanmış ve belirli dönemlerde bu yönetmelikler güncelleştirilmiştir. Son olarak “Türkiye Bina Deprem Yönetmeliği”1.1.2019 tarihinde yürürlüğe girmiş, bu yönetmelik ile hem deprem tehlike haritası güncellenmiş hem de parametre hesaplamalarda yeni yaklaşımlar getirilmiştir. Deprem sırasında yapıları etkileyecek kuvvetler statik ve dinamik yöntemlerle belirlenebilmektedir. Fakat hesaplamaları daha pratik hale getirmek için statik yöntem olan spektral analiz yöntemi çok yaygın bir şekilde kullanılmaktadır. $\mathrm{Bu}$ yöntem ise deprem yönetmeliğinde tasarım spektrumu olarak isimlendirilmiştir. Bu çalışmada, Erzurum ve Erzincan ili için farklı zemin türleri dikkate alınarak, 2007 Deprem Bölgelerinde Yapılacak Binalar Hakkında Yönetmelik (DBYBHY-2007) ve Türkiye Bina Deprem Yönetmeliğine (TBDY-2018) göre spektral ivme değerleri hesaplanmıştır. Tasarım spektrumlarının hesaplanacağı konumlar 1996 deprem bölgeleri haritasına göre birinci (Erzincan) ve ikinci (Erzurum) deprem bölgesinde bulunmaktadır. Yapılması planlanan yapı için 50 yılda aşılma olasılığ 1 \% 10 olan (geri dönüş periyodu 475 yıl, Deprem Yer Hareket Düzeyi-2) bir deprem için ivme spektrumları hesaplanmıştır. Tasarım spektrumları grafiksel ve tablo olarak hazırlanmış, aralarındaki

65 | P a g e

www.iiste.org 
fark ortaya koyulmuştur. Özellikle TDBY 2018'in eski yönetmelikten en büyük farklarından biri, deprem bölgesi kavramının kaldırılarak doğrudan yer ivmesi kavramının getirilmesidir. Diğer bir fark ise, zemin gruplarının değiş̧irilmesidir. Bu parametrelerin daha gerçeğe yakın olmasından dolayı TBDY 2018 ile yapılan hesaplamaların daha güvenilir olduğunu göstermektedir.

Anahtar Kelimeler: Deprem Tehlike Haritası, Spektral İvme, TBDY 2018, DBYBHY 2007

\section{Giriş}

Ülkemiz tarihi boyunca yıkıcı depremlere maruz kalmasından dolayı Ulusal Deprem Stratejisi ve Eylem Planı (UDSEP-2023) geliştirilmiş ve bu eylem planı içerisinde Türkiye Sismik Tehlike Haritası güncellenmiştir. Aynı eylem planı kapsamında bina yönetmeliği de güncellenmiş ve 01.01.2019 tarihinde yürürlüğe girmiştir. Yeni yönetmeliğin en büyük yeniliklerinden biri, tasarım spektrum hesaplamalarında, deprem bölgeleri kavramının terk edilmesi ve bunun yerine deprem tehlike haritasından elde edilen ivme değerlerinin kullanılmaya başlanılmasıdır. Deprem yer hareketi spektrumu, diğer adı ile davranış spektrumu, gözönüne alınan bir deprem yer hareketinin etkisi altında, belirli bir sönüm oranı için doğal titreşim periyodu $\mathrm{T}$ olan doğrusal elastik tek serbestlik dereceli bir sistemde meydana gelen maksimum toplam ivmenin (spektral ivme) veya maksimum yapısal yerdeğiştirmenin (spektral yerdeğiştirme) T'ye bağlı olarak ifade edildiği bir fonksiyondur (URL-1).

Gökbulut ve Sevim (2017), 2007 ve 2018 yönetmeliklerini karşılaştırmak için Yıldız Teknik Üniversitesi Davutpaşa Kampüsünde iki nokta seçip, bu noktalar için tasarım spektrumlarını hesaplamışlardır. Yapıya etki eden spektral ivme değerlerinin, 2018 yönetmeliğine göre kısa periyodlarda daha büyük değerler verdiğini ve bu farkın kötü zemin koşullarında daha da arttı̆̆ııı belirtmişlerdir.

Keskin ve Bozdoğan (2018), 2007 ve 2018 deprem yönetmeliklerini Kırklareli özelinde incelemişlerdir. Kırklareli il merkezinde seçilen bir nokta için tasarım spektrumlarını iki farklı zemin koşulu dikkate alınarak her iki yönetmelik için de hesaplamışlardır. Yapılan karşılaştırma sonucunda, 2018 yönetmeliği kullanılarak hesaplanan tasarım ivme değerlerinde ciddi oranda artış olduğu ve bu artışın Kırklareli özelinde daha gerçekçi sonuç verdiğini belirtmişlerdir.

Öztürk (2018), 2018 deprem yönetmeliğini değerlendirmek için İç Anadolu bölgesinde 1996 deprem bölge haritasına göre sırasıyla 1., 2., 3. ve 4. bölgede bulunan Kırşehir, Eskişehir, Kayseri ve Konya illerini göz önüne almışlardır. Elde ettikleri sonuçlara göre, yenilenen zemin sınıflaması, güncelleştirilen deprem tehlike haritası ve hesaplamalardaki yeniliklerin sonuçları olumlu yönde etkilediği çıkarımını yapmışlardır.

Koçer vd. (2018), Kocaeli, Eskişehir, Kayseri ve Konya illeri için spektral ivme değerlerini her iki yönetmeliği de kullanarak hesaplamışlardır. Özellikle zayıf zemin gruplarında 2018 yönetmeliğinin daha güvenilir olduğunu açıkça ifade etmişlerdir.

$\mathrm{Bu}$ çalı̧̧manın amacı, 2018 Türkiye Bina Deprem Yönetmeliği (TBDY) kullanılarak tasarım spektrumlarının elde edilmesi ve bu spektrumların Deprem Bölgelerinde Yapılacak Binalar Hakkında Yönetmelik (DBYBHY 2007)'ten elde edilen tasarım spektrumları ile karşılaştırılmasıdır. Bu amaç için Erzurum ve Erzincan illerinden birer nokta seçilmiştir. Bu noktalara ait ivme değerleri Türkiye Deprem Tehlike Haritasından elde edilmiş, Matlab ortamında geliştirilen programda her iki yönetmelik için tasarım spektrumları elde edilmiştir. Tasarım spektrumları elde edilirken hem farklı deprem davranış modelleri hem de farklı zemin türleri dikkate alınmıştır.

\section{2. Çalışma Alanının Depremselliği}

\subsection{Erzurum İlinin Depremselliği}

Erzurum ve civarı depremsellik açısından çok aktif olan Kuzey Anadolu, Doğu Anadolu ve Kuzey Doğu Anadolu Fayları etkisi altında bulunmaktadır (Şekil 1a, b). Çalışma alanında hem aletsel hem de tarihsel dönemde birçok yıkıcı deprem oluşmuş ve büyük ölçüde can ve mal kaybına neden olmuştur. $\mathrm{Bu}$ depremlerden başlıcaları; 26 Aralık 1939'da Erzincan, 24 Kasım 1976 Çaldıran, 30 Ekim 1983 HorasanNarman, 7 Aralık 1988 Spitak-Ermenistan ve 23 Ekim 2011 Tabanlı (Van) Ms = 7.2 depremleridir (Ambraseys, 2001; Cisternas vd., 1989; Eyidoğan vd., 1991; Irmak vd., 2012; Tan vd., 2008).

25 Mart 2004 Perşembe günü, Erzurum ili Aşkale ilçesinin yaklaşık $17 \mathrm{~km}$ doğusunda, saat 21.30'da (yerel saat) orta büyüklük $(\mathrm{Mw}=5.6)$ ve sığ-odaklı $(\mathrm{h}=10 \mathrm{~km})$ bir deprem meydana gelmiştir. $\mathrm{Bu}$ depremden üç gün sonra, 28 Mart 2004 Pazar günü, saat 06.51 'de (yerel saat), yine orta büyüklükte $\left(\mathrm{M}_{\mathrm{w}}\right.$ $=5.5)$ ve sığ-odaklı $(\mathrm{h}=5 \mathrm{~km})$ bir deprem meydana gelmiştir. Her iki deprem de Erzurum şehri, Aşkale, Ilıca, Çat ilçeleri, Kandilli ilçesi ve aynı bölgede yer alan bir dizi köyü kapsayan bir alan üzerinde hissedilmiştir. Bu depremler nedeni ile özellikle Aşkale ilçesi civarındaki köylerde 9 kişi yaşamını yitirmiş ve yaklaşık 1300 yapı ağır hasar görmüştür. Bu bölge aktif tektoniği nedeni ile yerbilimcilerin 
dikkatini çekmekte ve çok sayıda güncel çalışma bulunmaktadır (Koçyiğit (2013), Öztürk ve Bayrak (2005), Üner vd., (2010), Koçyiğit ve Canoğlu (2017), Özer (2019a), Özer (2019b)).
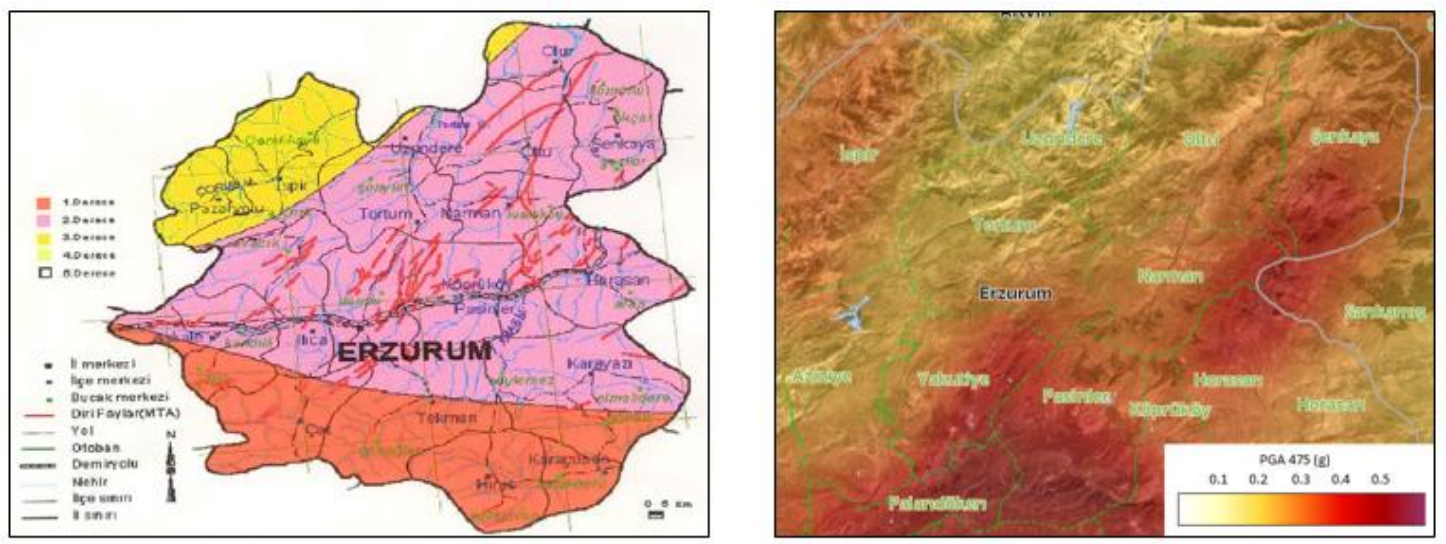

Şekil 1. a)“1996 Deprem Bölgeleri Haritasına” göre deprem tehlikesi durumu, b) 2018 Türkiye Deprem Tehlike Haritasina göre deprem tehlike durumu

\subsection{Erzincan İlinin Depremselliği}

Erzincan ilinin küçük bir bölümü hariç geri kalan kısmı 1996 deprem bölgeleri haritasına göre birinci derece deprem bölgesindedir (Şekil 2a) ve 2018 Türkiye deprem tehlike haritasına göre ise 50 y1lda $\% 10$ aşılma olasılığına göre ivme değerleri 0.5 g'den yüksektir (Şekil $2 b$ ). Ayrıca, Erzincan ve civarında hem aletsel hem de tarihsel dönemde hasar yapıcı birçok deprem meydana gelmiş ve bu depremler sonucunda çok sayıda can ve mal kaybı yaşanmıştır (URL-2, URL-3). Türkiye'de son yüzyılda yaşanan en büyük deprem de Erzincan'da meydana gelmiş $\left(1939, M_{S}=7.9\right)$ ve bu deprem sonucunda yaklaşı 33 bin kişi hayatını kaybetmiştir. İlk deprem yönetmeliği çalışmaları bu depremden sonra başlamıștır. Erzincan ve yakın çevresinde tarihsel ve aletsel dönemde meydana gelmiş büyük depremler, gelecekte benzer afetlerin olabileceğine işaret etmektedir (Özşahin ve Eroğlu, 2019).
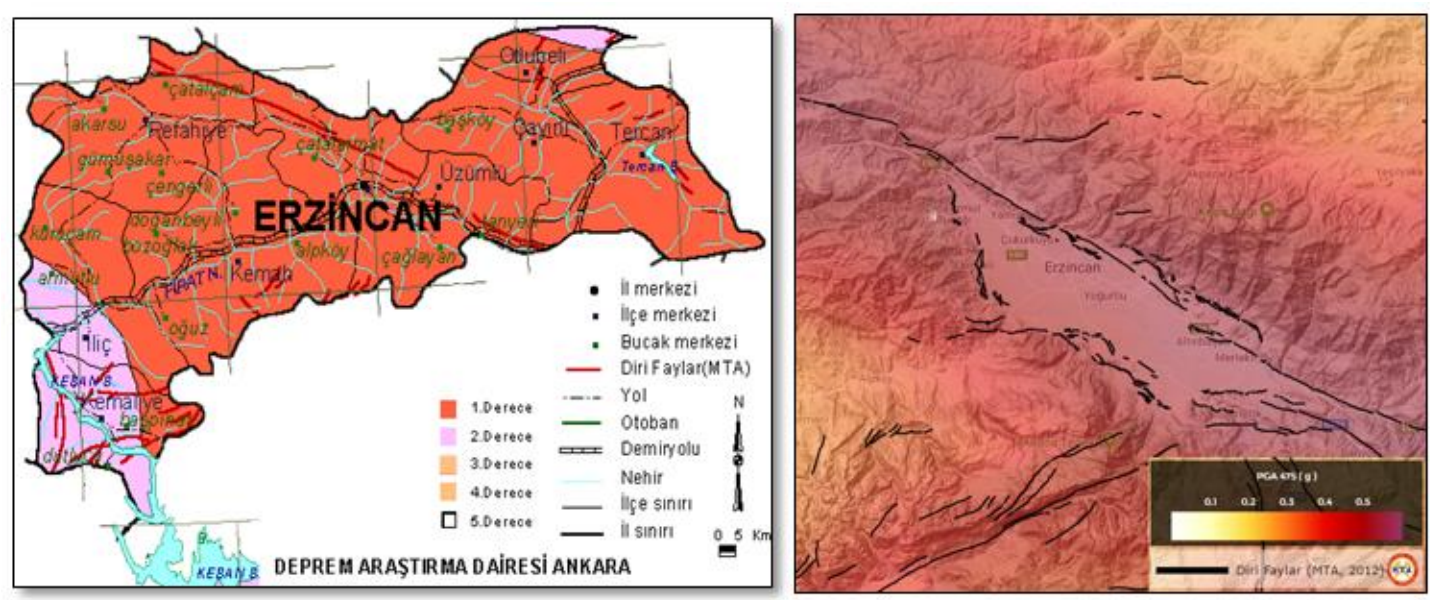

Şekil 2. a)“1996 Deprem Bölgeleri Haritasına” göre deprem tehlikesi durumu, b) 2018 Türkiye Deprem Tehlike Haritasına göre deprem tehlike durumu

\section{Tasarım Spektrumlarının Hesaplanması}

Yeni yönetmelik ile birlikte tasarım spektrumu hesaplarken kullanılan sabit $T_{A}-T_{B}$ periyodu değerleri terk edilmiş olup, bu parametrelerin hesabı kısa ve uzun periyot ( $\mathrm{T}=0.2 \mathrm{~s}$ ve $\mathrm{T}=1 \mathrm{~s})$ değerlerine karşılık gelen $\mathrm{S}_{\mathrm{S}}$ ve $\mathrm{S}_{1}$ değerleri kullanılarak yapılmaktadır (TBDY Madde 2.3.2.1). Bu katsayılar, web uygulamasindan (https://tdth.afad.gov.tr/TDTH/main.xhtml) elde edilmektedir. Katman kontrolü bölümünden deprem durumuna göre istenilen $S_{S}(2475-475-72-43)$ ve $S_{1}$ (2475-475-72-43) haritas1 çizdirilir. Daha sonra bilgi al bölümünden koordinat veya adres girilerek istenilen noktanın $S_{S}$ ve $S_{1}$ değerleri elde edilir. Hesaplamalar ile ilgili tablolar yönetmeliğin 2.3. bölümünde detaylı olarak anlatıldığı için bu çalışmada o kısımlara değinilmeyecektir. 
Türk bina deprem yönetmeliğine göre yatay tasarım spektrumu ivmesi, $\mathrm{S}_{\mathrm{ae}}(\mathrm{T})$; Şekil 3'de gösterilen dört farklı bölgeye göre yerçekimi ivmesi, g, cinsinden aşağıdaki denklemler kullanılarak hesaplanmaktadır.
$\mathrm{S}_{\mathrm{ae}}(\mathrm{T})=\left(0.4+0.6 \mathrm{~T} / \mathrm{T}_{\mathrm{A}}\right) \mathrm{S}_{\mathrm{DS}}$
$\left(0 \leq \mathrm{T} \leq \mathrm{T}_{\mathrm{A}}\right)$
$\mathrm{S}_{\mathrm{ae}}(\mathrm{T})=\mathrm{S}_{\mathrm{DS}}$
$\left(\mathrm{T}_{\mathrm{A}}<\mathrm{T} \leq \mathrm{T}_{\mathrm{B}}\right)$
$\mathrm{S}_{\mathrm{ae}}(\mathrm{T})=\mathrm{S}_{\mathrm{D} 1} / \mathrm{T}$
$\left(\mathrm{T}_{\mathrm{B}}<\mathrm{T} \leq \mathrm{TL}\right)$
$\mathrm{S}_{\mathrm{ae}}(\mathrm{T})=\mathrm{S}_{\mathrm{D} 1}\left(\mathrm{~T}_{\mathrm{L}} / \mathrm{T}^{2}\right)$
$\left(\mathrm{T}_{\mathrm{L}}<\mathrm{T}\right)$

Elastik tasarım spektrumunun $\mathrm{T}_{\mathrm{A}}$ ve $\mathrm{T}_{\mathrm{B}}$ köşe periyodları, $\mathrm{S}_{\mathrm{DS}}$ ve $\mathrm{S}_{\mathrm{D} 1}$ (TBDY, Bölüm 2.3.2.2) katsayılarına bağlı olarak değişim göstermektedir $\left(\mathrm{T}_{\mathrm{A}}=0.2 * \mathrm{~S}_{\mathrm{DS}} / \mathrm{S}_{\mathrm{D} 1} ; \mathrm{T}_{\mathrm{B}}=\mathrm{S}_{\mathrm{D} 1} / \mathrm{S}_{\mathrm{DS}}\right) .2007$ Deprem yönetmeliğinde ise köşe periyodları zemin sınıflarına göre sabit bir değer olarak verilmiştir. Denklem 1'de bulunan $T_{L}$ ise sabit yer değiştirme bölgesine geçiş periyodu olarak belirtilmiş ve hesaplarda $T_{L}=6$ s olarak alınacaktır.

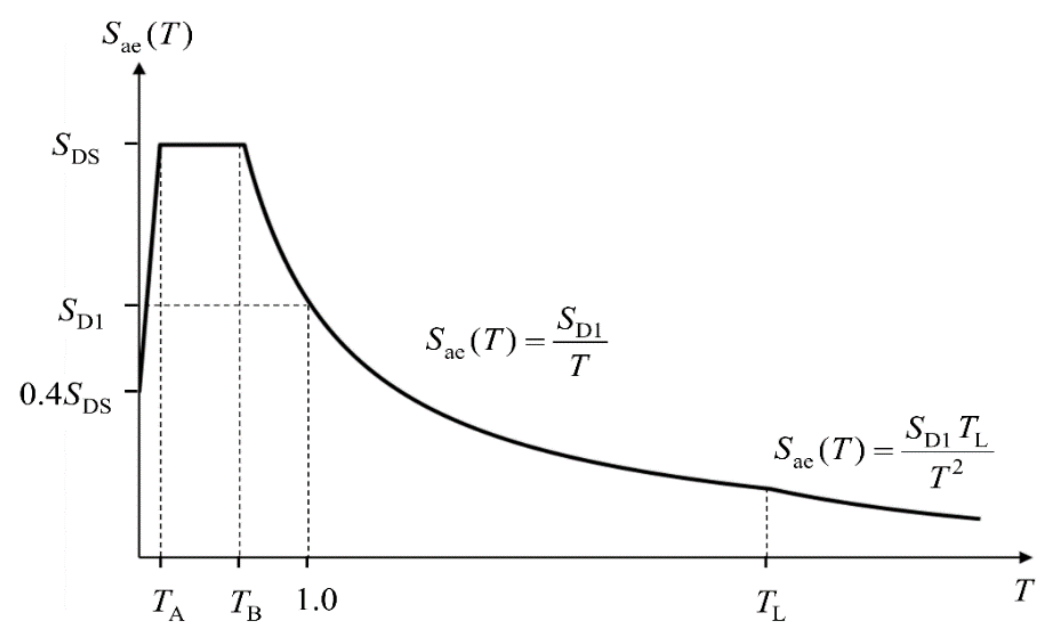

Şekil 3. Yatay Elastik tasarım spektral ivmesi Sae (T)'nin doğal titreşim periyoduna göre değişimi (TBDY, 2018)

\subsection{Tasarım Spektrumlarının Hesaplanması için Tasarlanan Program}

Bu çalışma kapsamında tasarım spektrumlarını hesaplamak için Matlab programı kullanılarak bir yazılım geliştirilmiştir (Şekil 4). Bu yazılıma deprem tehlike haritasından elde edilen $\mathrm{S}_{\mathrm{S}}$ ve $\mathrm{S}_{1}$ değerleri girilip, zemin türü seçildikten sonra TBDY 2018 yönetmeliğine göre tasarım spektrumları hesaplanıp, hesaplanan değerlerin grafiği çizdirilmektedir. Hesaplanan değerlerin 2007 yönetmeliği ile de karşılaştırılması yapılabilmekte ve sonuçlar Excel dosyasına yazdırılabilmektedir.

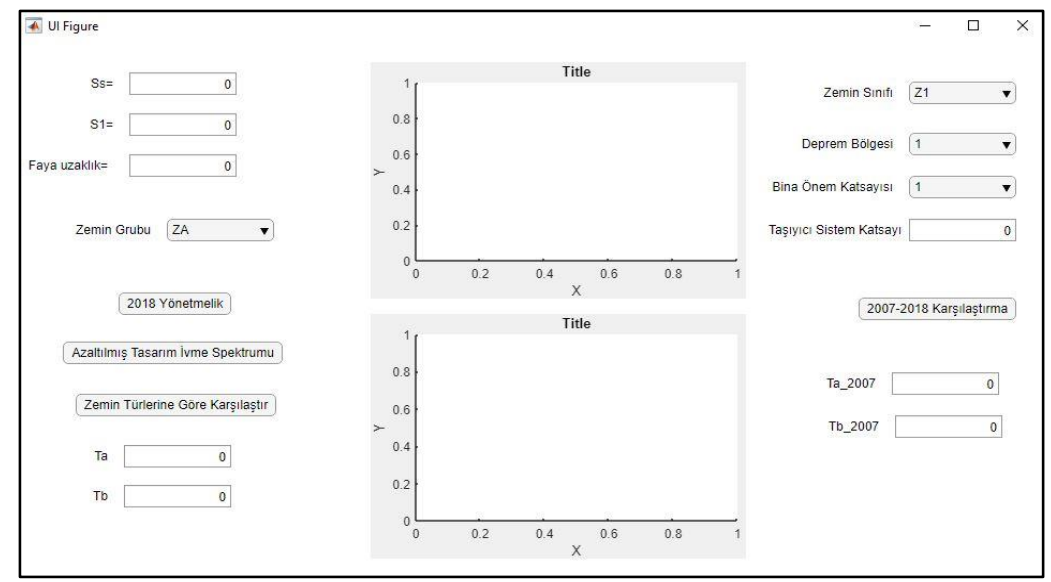

Şekil 4. Yatay elastik tasarım spektrumlarını hesaplamak için tasarlanan program (Bu program Matlab 2019a kullanılarak hazırlanmıştır). 


\section{Sonuçlar}

Erzurum il merkezinde bulunan Atatürk Üniversitesi kampüsünde yapılması planlanan yap1 (Boylam:41.2391ํD, Enlem:39.8989ํK) 1996 deprem bölgeleri haritasına göre ikinci deprem bölgesinde bulunmaktadır (Şekil 1a). Erzincan ilinde ise Binali Yıldırım Üniversitesi kampüsünde (Boylam:39.51249 $\mathrm{D}$, Enlem:39.75976 ${ }^{\circ} \mathrm{K}$ ) 1996 deprem bölgeleri haritasına göre birinci deprem bölgesinde bulunan bir yapı seçilmiştir. Bu yapılara ait tasarım spektrumları 2018 yönetmeliğine göre farklı deprem durumları ve farklı zemin koşulları dikkate alınarak hesaplanmıştır (Şekil 5, 7). 2018 ve 2007 yönetmeliklerini karşılaştırmak için de 50 yılda aşılma olasılığ $\% 10$ olan (DD-2) deprem için tasarım spektrumları hesaplanmıştır (Şekil 6, 8). 2007 ve 2018 yönetmeliklerinde zemin sınıflama tablosu da değiştirilmiş olup zemin sınıfları tam olarak birbirine denk gelmemektedir. Fakat karşılaştırma yapabilmek için 2007 yönetmeliğine göre sırası ile Z3 ve Z4 olan zemin sınıflarını yeni yönetmelikte ZC ve ZE'ye denk geldiği varsayımı yapılmıştır. Erzurum ili için hesaplamalarda kullanılan parametreler Tablo 1'de, Erzincan ili için kullanılan parametreler ise Tablo 3'de belirtilmiştir.
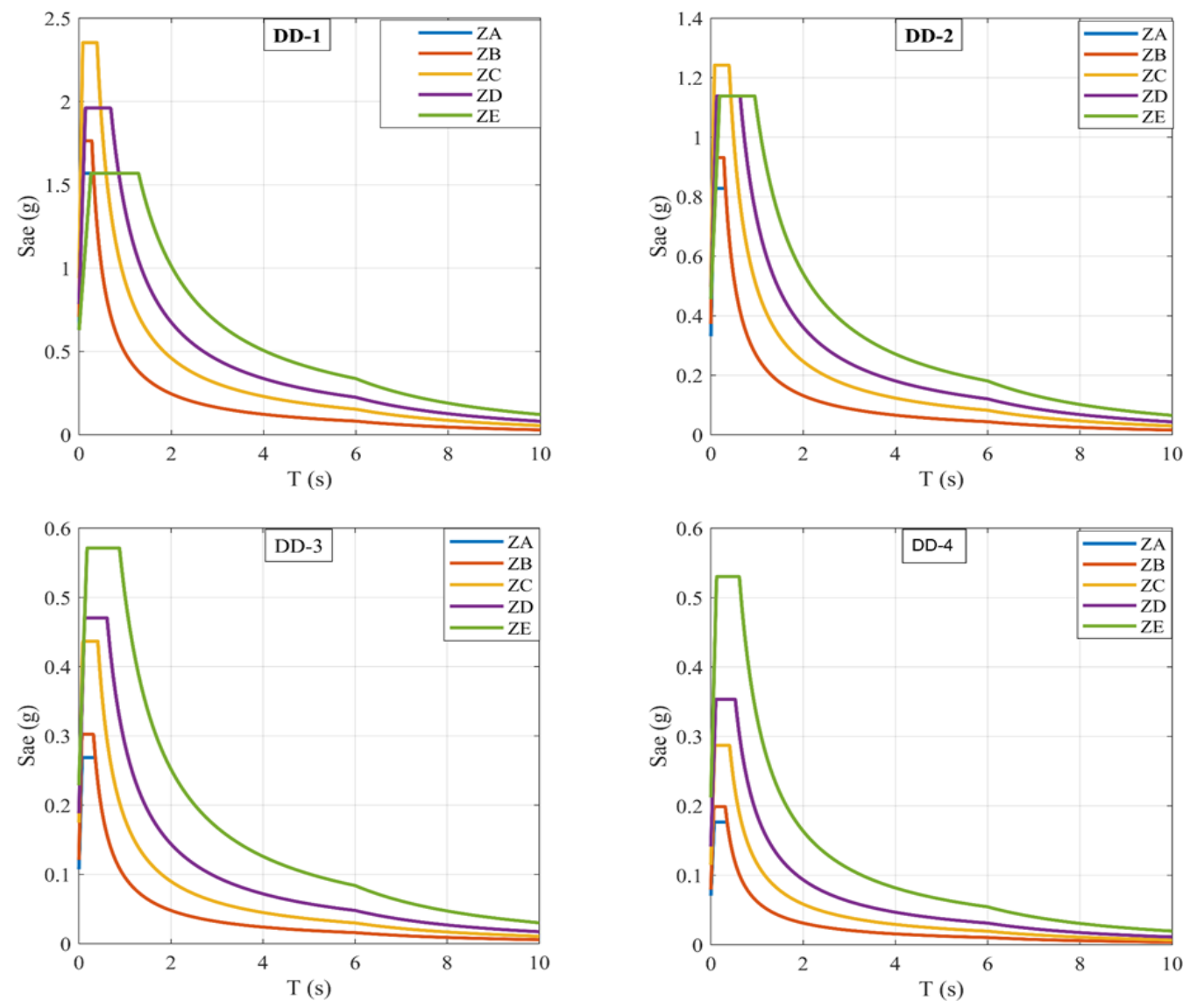

Şekil 5. Erzurum ilinde seçilen nokta için farklı zemin koşulları dikkate alınarak hesaplanan yatay elastik tasarım spektrumları 

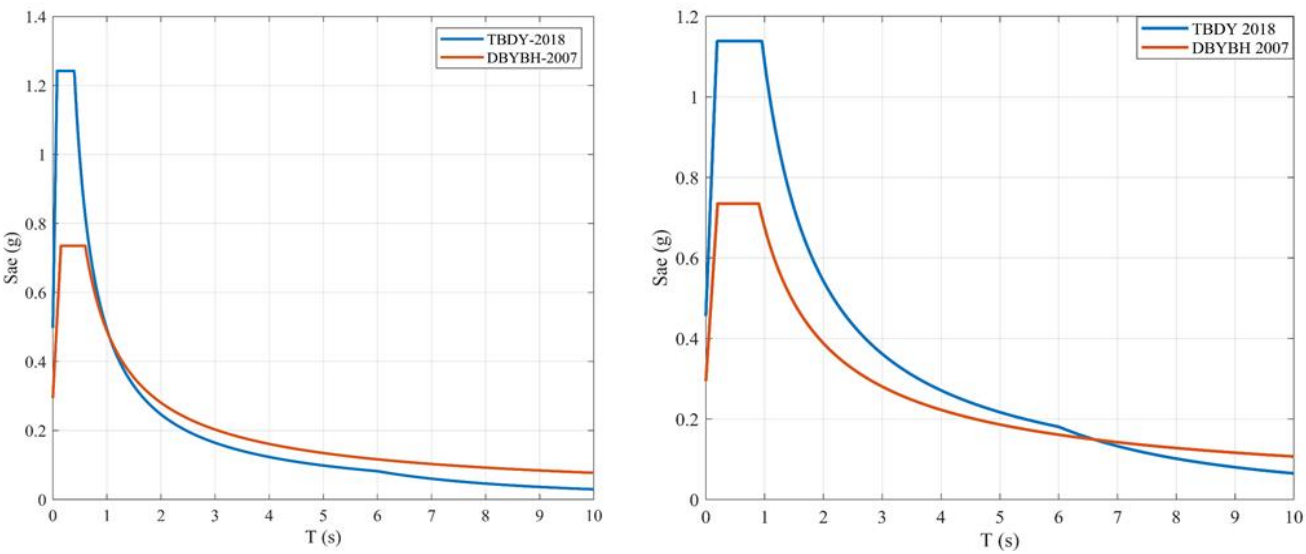

Şekil 6. Erzurum ili için, a) TBDY 2018 ZC sınıfı ile DBYBHY 2007 Z3 sınıfı karşılaştırılması, b) TBDY 2018 ZE sınıfı ile DBYBHY 2007 Z4 sınıfı karşılaştırılması
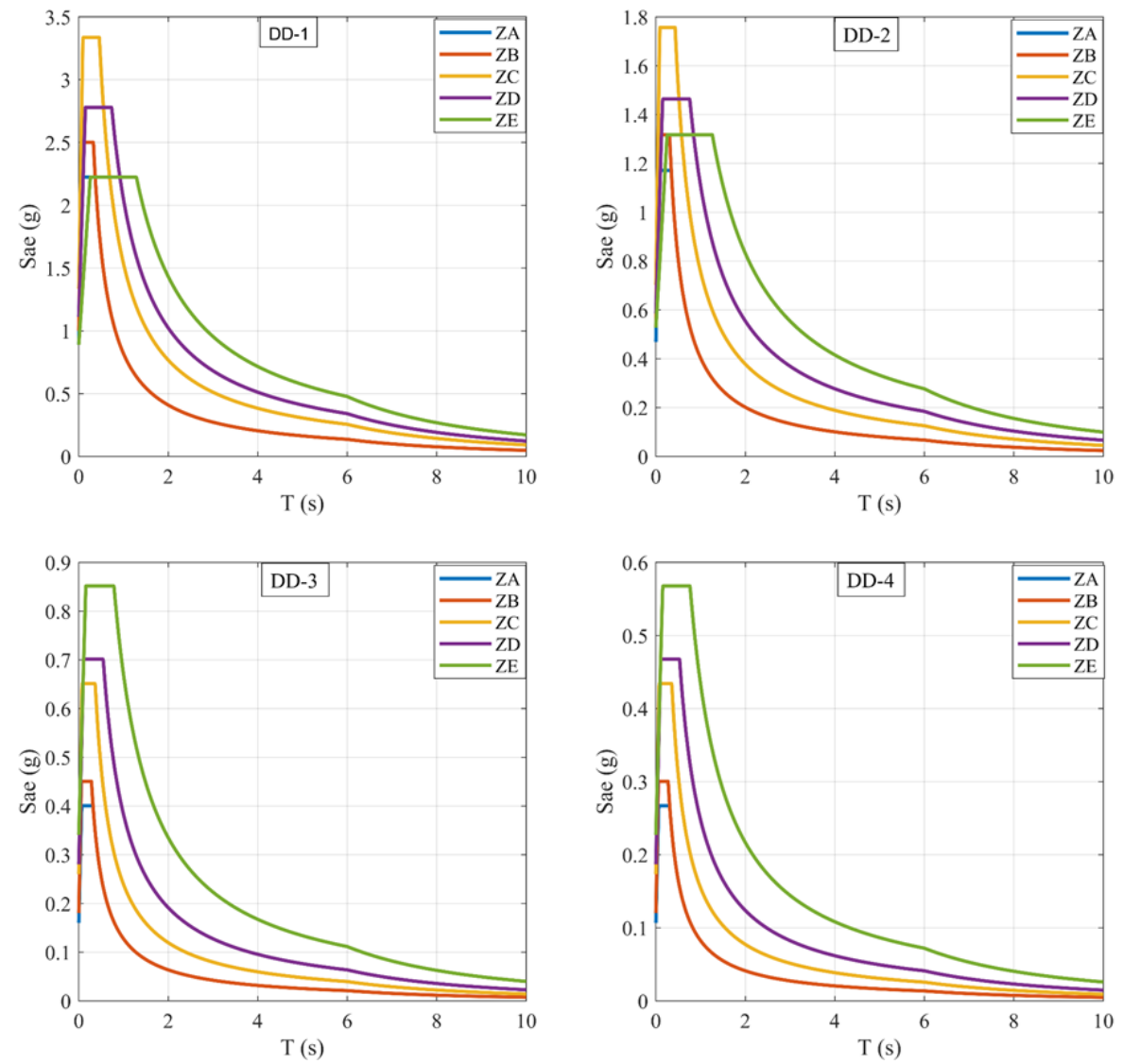

Şekil 7. Erzincan ilinde seçilen nokta için farklı zemin koşulları dikkate alınarak hesaplanan yatay elastik tasarım spektrumları 
Tablo 1. Erzurum ili için deprem tehlike haritasından elde edilen değerler

\begin{tabular}{|l|l|l|l|l|l|}
\hline $\begin{array}{l}\text { Deprem } \\
\text { Durumu }\end{array}$ & PGA & PGV & SS & S1 & Lf* \\
\hline DD-1 & $0.787 \mathrm{~g}$ & $48.450 \mathrm{~cm} / \mathrm{sn}$ & $1.961 \mathrm{~g}$ & $0.511 \mathrm{~g}$ & $1.0 \mathrm{~km}$ \\
\hline DD-2 & $0.434 \mathrm{~g}$ & $26.368 \mathrm{~cm} / \mathrm{sn}$ & $1.035 \mathrm{~g}$ & $0.274 \mathrm{~g}$ & $1.0 \mathrm{~km}$ \\
\hline DD-3 & $0.145 \mathrm{~g}$ & $9.171 \mathrm{~cm} / \mathrm{sn}$ & $0.336 \mathrm{~g}$ & $0.100 \mathrm{~g}$ & $1.0 \mathrm{~km}$ \\
\hline DD-4 & $0.096 \mathrm{~g}$ & $5.955 \mathrm{~cm} / \mathrm{sn}$ & $0.221 \mathrm{~g}$ & $0.065 \mathrm{~g}$ & $1.0 \mathrm{~km}$ \\
\hline
\end{tabular}

* Faya olan uzaklık (Bu değer deprem tehlike haritası interaktif web uygulaması kullanılarak elde edilmiştir)

Tablo 2. Erzurum ilin için farklı zemin koşullarına göre hesaplanan $T_{A}-T_{B}$ periyotları

\begin{tabular}{|c|c|c|c|c|c|c|}
\hline & & ZA & ZB & ZC & ZD & ZE \\
\hline \multirow{2}{*}{ DD-1 } & $\mathrm{T}_{\mathrm{A}}$ & 0.0620 & 0.056 & 0.078 & 0.1376 & 0.258 \\
\cline { 2 - 7 } & $\mathrm{T}_{\mathrm{B}}$ & 0.3127 & 0.278 & 0.391 & 0.6879 & 1.290 \\
\hline \multirow{2}{*}{ DD-2 } & $\mathrm{T}_{\mathrm{A}}$ & 0.064 & 0.056 & 0.079 & 0.127 & 0.191 \\
\cline { 2 - 7 } & $\mathrm{T}_{\mathrm{B}}$ & 0.318 & 0.282 & 0.397 & 0.635 & 0.953 \\
\hline \multirow{2}{*}{ DD-3 } & $\mathrm{T}_{\mathrm{A}}$ & 0.071 & 0.063 & 0.082 & 0.122 & 0.177 \\
\cline { 2 - 7 } & $\mathrm{T}_{\mathrm{B}}$ & 0.357 & 0.318 & 0.412 & 0.612 & 0.882 \\
\hline \multirow{2}{*}{ DD-4 } & $\mathrm{T}_{\mathrm{A}}$ & 0.071 & 0.063 & 0.081 & 0.106 & 0.124 \\
\cline { 2 - 7 } & $\mathrm{T}_{\mathrm{B}}$ & 0.352 & 0.314 & 0.407 & 0.529 & 0.618 \\
\hline
\end{tabular}

Tablo 3. Erzincan ili için deprem tehlike haritasından elde edilen değerler

\begin{tabular}{|c|c|c|c|c|c|}
\hline $\begin{array}{c}\text { Deprem } \\
\text { Durumu }\end{array}$ & PGA & PGV & SS & S1 & Lf* \\
\hline DD-1 & $1.121 \mathrm{~g}$ & $76.528 \mathrm{~cm} / \mathrm{sn}$ & $2.780 \mathrm{~g}$ & $0.853 \mathrm{~g}$ & $0.22 \mathrm{~km}$ \\
\hline DD-2 & $0.610 \mathrm{~g}$ & $40.126 \mathrm{~cm} / \mathrm{sn}$ & $1.464 \mathrm{~g}$ & $0.420 \mathrm{~g}$ & $0.22 \mathrm{~km}$ \\
\hline DD-3 & $0.218 \mathrm{~g}$ & $12.953 \mathrm{~cm} / \mathrm{sn}$ & $0.501 \mathrm{~g}$ & $0.133 \mathrm{~g}$ & $0.22 \mathrm{~km}$ \\
\hline DD-4 & $0.148 \mathrm{~g}$ & $8.376 \mathrm{~cm} / \mathrm{sn}$ & $0.334 \mathrm{~g}$ & $0.086 \mathrm{~g}$ & $0.22 \mathrm{~km}$ \\
\hline
\end{tabular}

Tablo 4. Erzincan ilin için farklı zemin koşullarına göre hesaplanan $\mathrm{T}_{\mathrm{A}}-\mathrm{T}_{\mathrm{B}}$ periyotları

\begin{tabular}{|l|l|l|l|l|l|l|}
\hline & & ZA & ZB & ZC & ZD & ZE \\
\hline \multirow{2}{*}{ DD-1 } & $\mathrm{T}_{\mathrm{A}}$ & 0.074 & 0.065 & 0.092 & 0.147 & 0.258 \\
\cline { 2 - 7 } & $\mathrm{T}_{\mathrm{B}}$ & 0.368 & 0.327 & 0.460 & 0.736 & 1.289 \\
\hline \multirow{2}{*}{ DD-2 } & $\mathrm{T}_{\mathrm{A}}$ & 0.069 & 0.0612 & 0.086 & 0.1515 & 0.2525 \\
\cline { 2 - 7 } & $\mathrm{T}_{\mathrm{B}}$ & 0.344 & 0.306 & 0.430 & 0.7574 & 1.262 \\
\hline \multirow{2}{*}{ DD-3 } & $\mathrm{T}_{\mathrm{A}}$ & 0.063 & 0.056 & 0.074 & 0.109 & 0.157 \\
\cline { 2 - 7 } & $\mathrm{T}_{\mathrm{B}}$ & 0.319 & 0.283 & 0.368 & 0.546 & 0.787 \\
\hline \multirow{2}{*}{$\mathrm{DD}-4$} & $\mathrm{~T}_{\mathrm{A}}$ & 0.062 & 0.055 & 0.0713 & 0.106 & 0.1527 \\
\cline { 2 - 7 } & $\mathrm{T}_{\mathrm{B}}$ & 0.309 & 0.275 & 0.3565 & 0.529 & 0.7634 \\
\hline
\end{tabular}

Her iki yapı için de DD-1 ve DD-2 koşulu için en büyük spektral ivme değerleri ZC zemin sınıfında elde edilmesine rağmen, DD-3 ve DD-4 koşullarında ZE zemin sınıfı için en büyük ivme değerleri elde 
edilmiştir. $T_{A}$ ve $T_{B}$ köşe periyotları arasındaki farkta, DD-1'den DD-4'e doğru gidildikçe azaldığ görülmektedir. 2018 ve 2007 yönetmelikleri göre elde edilen sonuçlar karşılaştırıldığında ise, her iki zemin koşulu içinde 2018 yönetmeliği daha yüksek ivme değerleri vermektedir (Şekil 6, 8). Fakat Erzurum ili için ZC-Z3 kıyaslamasında yaklaşık 1 sn periyodundan sonra yeni yönetmeliğe göre daha düşük ivme değerleri elde edilmesine rağmen, Erzincan ili için ise bu değer yaklaşık 2 sn'dir. ZE-Z4 kıyaslamasında ise Erzurum için 6.5 sn periyodundan sonra bu durum gözlenmesine rağmen, Erzincan için yaklaşık 7 sn'den sonra bu durum gözlenmiştir. 2018 yönetmeliğinde daha kötü zemin koşullarında $\mathrm{T}_{\mathrm{A}}-\mathrm{T}_{\mathrm{B}}$ arasındaki farkın arttığı ve daha gerçekçi spektrumlar elde edildiği görülmektedir (Tablo 2, 4).

Sonuç olarak, 2018 deprem yönetmeliği ile birlikte kullanılmaya başlanan zemin sınıflaması, Türkiye deprem tehlike haritası ve spektral parametre hesabındaki yeniliklerin, spektrum hesaplamasına pozitif katkı yaptığı ve daha gerçekçi spektrumların elde edildiği söylenebilir. Spektrumlardaki doğruluk payını arttırmak için, zemin özelliklerin yerinde jeofizik, jeolojik ve geoteknik etütlerle belirlenmesinin gerekliliği de aşikârdır.
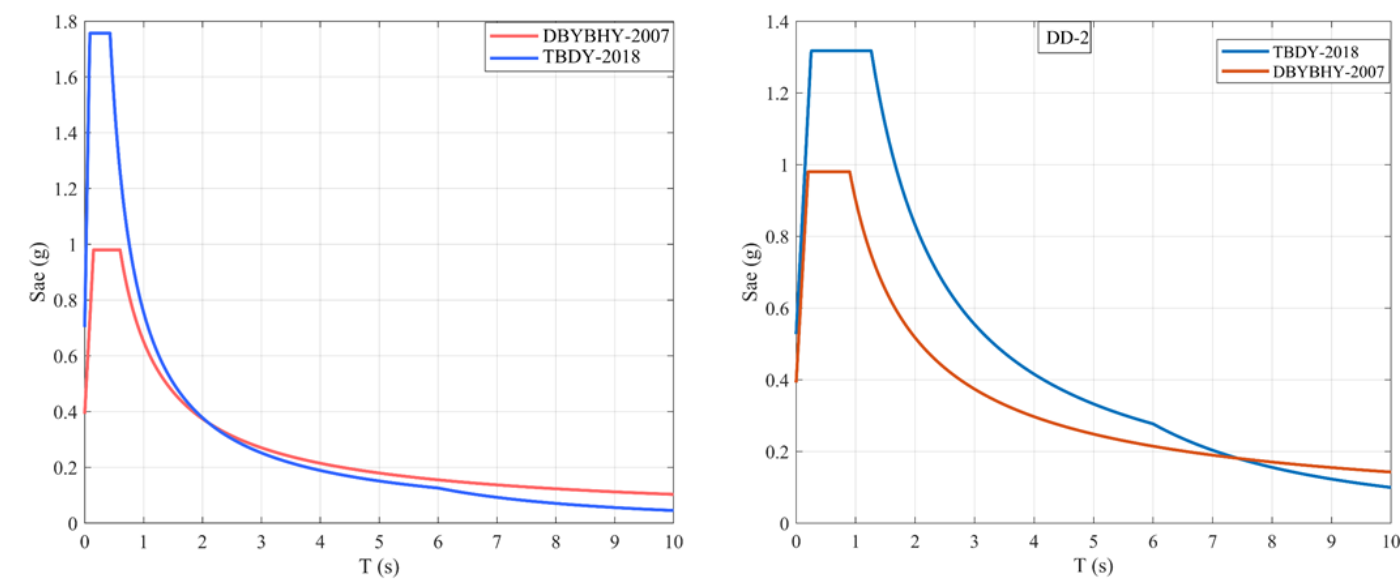

Şekil 8. Erzincan ili için, a) TBDY 2018 ZC sınıfı ile DBYBHY 2007 Z3 sınıfı karşılaştırılması, b) TBDY 2018 ZE sınıfı ile DBYBHY 2007 Z4 sınıfı karşılaştırılması

\section{Kaynakça}

URL-1;https://www.insaport.com/makale/yuksel-kaya/deprem-yer-hareketi-spektrumlari-nasilolusturulacak/

URL-2; http://www.koeri.boun.edu.tr/sismo/2/deprem-bilgileri/tarihsel-depremler/

URL-3; http://www.koeri.boun.edu.tr/sismo/2/deprem-bilgileri/buyuk-depremler/

Ambraseys, N. N. (2001). Reassesment of earthquakes. Geophysical Journal Internatinal, 145(2) 471-485.

Cisternas, A., Philip, H., J, C. B., Cara, M., Deschamps, A., Dorbath, L., \& Rivera, L. (1989). The Spitak (Armenia) Earthquake of 7 December 1988: Field Observations, Seismology and Tectonics. Nature, 339(6227), 675.

Deprem Bölgelerinde Yapılacak Binalar Hakkında Yönetmelik (2007). Ankara: Bayındırlık ve İskan Bakanlığ1.

Eyidoğan, H., Güçlü, U., Utku, Z., \& Değirmenci, E. (1991). Türkiye Büyük Depremleri Makrosismik Rehberi (1900-1988). İTÜ MF Jeofizik Mühendisliği Bölümü Yayınları.

Gökbulut, E., \& Sevim, B. (2017). Ytü Davutpaşa Kampüsündeki Yapılara Ait Tasarım Spektrumlarının TDBY 2016 ve DBYBHY 2007'ye Göre Kiyaslanması. 7. Geoteknik Seтроzуити, (s. 707-716). İstanbul. 
Irmak, T. S., Doğan, B., \& Karakaş, A. (2012). Source Mechanism of the 23 October, 2011, Van (Turkey) Earthquake $(\mathrm{M} \mathrm{w}=7.1)$ and Aftershocks with its Tectonic Implications. Earth, planets and space, 64(11), 991-1003.

Keskin, E., \& Bozdoğan, K. B. (2018). 2007 VE 2018 Deprem Yönetmeliklerinin Kırklareli İli Özelinde Değerlendirilmesi. Kırklareli University Journal of Engineering and Science, 4(1), 7490.

Koçer, M., Nakipoğlu, A., Öztürk, B., Al-Hagri, M. G., \& Arslan, M. H. (2018). Deprem Kuvvetine Esas Spektral İvme Değerlerinin TBDY 2018 ve TDY 2007'ye Göre Karşılaştırılması. Journal of Selcuk-Technic, 17(2), 43-58.

Koçyiğit, A. (2013). New field and seismic data about the intraplate strike-slip deformation in Van region, East Anatolian plateau, Eastern Turkey. Journal of Asian Earth Sciences, 62, 586-605.

Koçyiğit, A., \& Canoğlu, M. C. (2017). Neotectonics and seismicity of Erzurum pull-apart basin, East Turkey. Russian Geology and Geophysics, 58, 99-122 .

Özer, Ç. (2019a). Investigation of the Local Soil Effects of Erzurum and Its Surroundings Using SSR and HVSR Methods. DEU Journal of the Faculty of Engineering Journal of Science and Engineering, 21 (61), 247-257.

Özer, Ç. (2019b). Investigation of Soil Amplification in Lake Van Basin. Research Reviews in Engineering (Book Chapter) (s. 63-75, ISBN: 978-605-7631-38-1).

Özşahin, E., \& Eroğlu, İ. (2019). Erzincan Kentinde Yerel Zemin Özelliklerinin Deprem Duyarlılı̆̆ına Etkisi. Artvin Çoruh Üniversitesi Doğal Afetler Uygulama ve Araştırma Merkezi, $5(1), 41-57$.

Öztürk, M. (2018). 2018 Türkiye Bina Deprem Yönetmeliği ve Türkiye Deprem Tehlike Haritası İle İlgili İç Anadolu Bölgesi Bazında Bir Değerlendirme. Journal of Selcuk-Technic, 17(2), 31-42.

Öztürk, S., \& Bayrak, Y. (2005). 25 Mart 2004 Erzurum depremi, Md = 5.3, Artçı şok aktivitesi için sismisite parametreleri b ve $\mathrm{p}$ değerlerinin bölgesel değişimleri. II. Mühendislik Bilimleri Genç Arastirmacilar Kongresi, (s. 475-481). İstanbul.

Tan, O., Tapirdamaz, M. C., \& Yörük, A. (2008). The Earthquake Catalogues for Turkey. Turkish Journal of Earth Sciences, 17(2), 405-418.

Türkiye Deprem Bölgelerinde Yapllacak Binalar Hakkında Yönetmelik (2018). Ankara: Afet ve Acil Durum Yönetim Başkanlığı.

Üner, S., Yesilova, Ç., Yakupoglu, T., \& Üner, T. (2010). Pekismemis sedimanlarda depremlerle olusan deformasyon yapilari (sismitler): Van Gölü Havzasi, Dogu Anadolu. Yerbilimleri, 31/1, $53-66$. 